\title{
Corona Loss Minimization on High Voltage Transmission Line Network using Bundled Conductors.
}

\section{Crescent Onyebuchi Omeje}

\begin{abstract}
Electrical power generated and transmitted at a long distance away from the power stations is usually affected by inherent transmission line losses. The Ohmic and Corona losses which are predominantly common in power transmission lines are considered in this paper. These two losses are mathematically modeled with and without embedded bundled conductors. The resultant model which is a non-linear multivariable unconstrained optimized equation is minimized using the Hessian matrix determinant method for stability test purposes. The results obtained show that corona losses are minimized with embedded bundled conductors at a very low current value with large spacing distance between the bundled conductors. The decrease in the corona loss which is a consequence of spacing adjustment of the 2, 3, and 4 strands of bundled conductors was plotted using MATLAB 7.14. The plots obtained are in conformity with the inverse relation between corona loss and conductor spacing.
\end{abstract}

Keyword: Bundled Conductors, Corona-Loss, Hessian Matrix, Power Loss modelling, and Simulation.

\section{INTRODUCTION.}

The conventional and non-renewable energy generated in electrical form at various power stations are usually situated a long distance away from the load centre [1]. This long distance necessitates the need for an extensive network of conductors between the power stations and the load centres [1]. The electrical power generated at the power stations is prevalently transmitted by means of transmission lines which deliver bulk power from generating stations to the load centres and to consumer's terminal. The power losses along the transmission lines are usually reduced to the barest minimum for an effective and quality power delivery [2]. Many research works have been carried out on the analysis of power loss reduction in transmission lines. A comparison between corona loss and ohmic loss was analyzed in [3]. The corona and ohmic losses discussed were measured and evaluated for different transmission line under fair weather and rainy conditions but no emphasis was made to an embedded bundled conductors. Numphetch in 2011 worked on loss minimization using optimal power flow which was predicated upon swarm particle optimization. This research analysis was based on artificial intelligence and predictive method for loss minimization [4].

Revised Manuscript Received on February 05, 2020.

* Correspondence Author

Crescent Onyebuchi Omeje*, lecturer in the Department of Electrical/Electronic Engineering, University of Port Harcourt, Rivers State, Nigeria.

(C) The Authors. Published by Blue Eyes Intelligence Engineering and Sciences Publication (BEIESP). This is an open access article under the CC BY-NC-ND license (http://creativecommons.org/licenses/by-nc-nd/4.0/)
A multi-objective optimization method for power loss minimization and voltage stability has been evaluated in [5]. Abdullah also examined a transmission loss minimization using evolutionary computation for improved voltage stability [6]. A fuzzy multi-objective optimization and genetic algorithm based method has been applied to find optimum power system operating conditions as reported in [7]. A new method of calculating transmission power loss based on exact modelling of ohmic loss was presented in [8]. The approaches applied in the references mentioned above had limitations of using bundled conductors for corona loss minimization. This paper in a bid to ensure that appreciable reduction in corona loss is achieved applied spacing adjustment of $\mathbf{2}, \mathbf{3}$, and $\mathbf{4}$ strands of bundled conductors for corona loss minimization. It also considered a mathematical modelling for power losses using the Ohmic and corona loss equations. The resulting model was minimized using the classical unconstrained optimization technique involving a Hessian matrix.

\section{CORONA DISCHARGE AND POWER LOSS MODELLING.}

Corona discharge is a phenomenon which involves the ionization of the surrounding air of power conductors at a voltage greater than the critical breakdown voltage [9]. This process is usually characterized by a hissing sound which is accompanied by a bluish discharge with a production of ozone gases and flashover [9]. The corona and the ohmic losses contribute significantly to transmission line losses. Heat production and temperature rise in electrical conductors emanates from the current flow in the conductor. The rise in temperature of transmission line conductors increases the resistance of the conductor which invariably increases the conduction losses of the conductor. The ohmic loss for a heated conductor is given by equation (1) as reported in [10].

$$
\begin{aligned}
& \text { Ohmic }_{\text {Loss }}=\mathrm{I}^{2} \mathrm{R} \quad(\mathrm{Kw} / \mathrm{Km} / \text { phase }) \\
& \mathrm{R}=\frac{\rho L}{A} \quad(\Omega)
\end{aligned}
$$

The expression for the corona loss is presented in equation (3) in accordance with the reports in [11].

$$
\begin{aligned}
\text { Corona }_{\text {Loss }}= & \frac{242 \times(\mathrm{F}+25)}{\delta} \times \sqrt{\left(\frac{\mathrm{r}}{\mathrm{d}}\right)} \times\left(\mathrm{V}-\mathrm{V}_{0}\right)^{2} \\
& \times 10^{-5}(\mathrm{Kw} / \mathrm{Km} / \text { phase })
\end{aligned}
$$

The corona loss in terms of the cross-sectional area of the conductor is re-expressed in equation (4). 


$$
\begin{aligned}
\text { Corona }_{\text {Loss }}= & \frac{242 \times(\mathrm{F}+25)}{\delta} \times \sqrt[4]{\left(\frac{\mathrm{A}}{\pi \mathrm{d}^{2}}\right)} \times\left(\mathrm{V}-\mathrm{V}_{0}\right)^{2} \\
& \times 10^{-5}(\mathrm{Kw} / \mathrm{Km} / \text { phase })
\end{aligned}
$$

Total power loss on transmission lines is the summation of the Ohmic and Corona loss as given in equation (5).

$$
\begin{aligned}
\mathrm{T}_{\text {Loss }}= & \mathrm{I}^{2} \frac{\rho \mathrm{L}}{\mathrm{A}}+\frac{242 \times(\mathrm{F}+25)}{\delta} \times \sqrt[4]{\left(\frac{\mathrm{A}}{\pi \mathrm{d}^{2}}\right)} \\
& \times\left(\mathrm{V}-\mathrm{V}_{0}\right)^{2} \\
& \times 10^{-5}(\mathrm{Kw} / \mathrm{Km} / \text { phase })
\end{aligned}
$$

The air density factor is obtained from equation (6).

$$
\delta=\frac{3.92 \times b}{273+t}
$$

Where: $\rho$ is the resistivity of the conductor in $(\Omega \mathrm{m}) ; L$ is the length of the conductor in $(\mathrm{m})$; $\mathrm{A}$ is the cross-sectional area of the conductor in $\left(\mathrm{m}^{2}\right) ; \mathrm{F}$ is the frequency of the transmission voltage in $(\mathrm{Hz}) ; \delta$ is the air density factor; $\mathrm{r}$ is the radius of the conductor in $(\mathrm{m})$; $\mathrm{d}$ is the space between the transmission lines conductors in $(\mathrm{m})$; $\mathrm{V}$ is the operating voltage in $(\mathrm{V}) ; V_{0}$ is the critical disruptive voltage in $(\mathrm{V}), \mathrm{b}$ $=$ barometric pressure in $(\mathrm{cm} \mathrm{of} \mathrm{Hg})$ and $\mathrm{t}=$ temperature in ( $\left.{ }^{0} \mathrm{C}\right)$.

\section{III.BASIC CONCEPTS OF CONDUCTOR BUNDLING.}

Conductor bundling according to Ibe, A.O. implies having two or more conductors per phase in close proximity compared with the spacing of the conductors between phases [12]. Conductor bundling increases the effective radius of the lines conductor and also reduces the electric field strength near the conductors [13]. Therefore increasing the number of conductors in a bundle reduces the effects of corona discharge. Conductor bundling also reduces the high voltage gradient on the conductor for extra high voltage range above $230 \mathrm{kV}$ [14]. A bundled conductor can also be redefined as a conductor that is made up of two or more subconductors applied as one phase conductor [15]. Associated advantages of bundled conductors are as listed:
A. Reduced Reactance of the line
B. Reduced Voltage Gradient
C. Reduced Corona Loss
D. Reduced Radio Interference
E. Reduced Surge Impedance

An optimum sub-conductor spacing for bundled conductors always gives a minimum voltage gradient on the surface of sub-conductor as buttressed in equation (7).

$$
g=\frac{V\left(1+\frac{2 r}{S}\right)}{2 r \ln \frac{d}{\sqrt{r S}}}
$$

Where: S represents the separation between the subconductors in (m); $r$ is the radius of the conductor in (m); $d$ is the space between the transmission lines conductors in $(\mathrm{m})$; $\mathrm{V}$ is the operating voltage in $(\mathrm{V})$.

The different strands of bundled conductors are represented in Figures 1, 2, and 3 respectively.

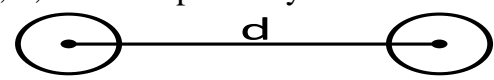

Figure 1. A Two-Strand Bundled Conductor

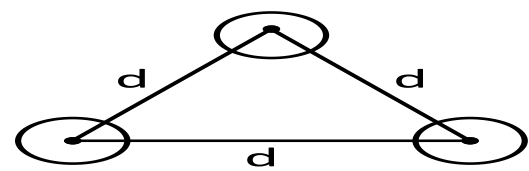

Figure 2. A Three-Strand Bundled Conductor

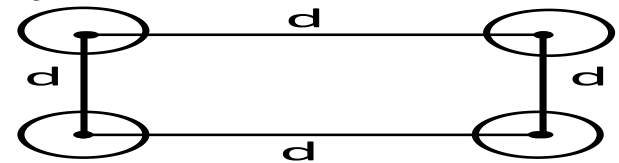

Figure 3. A Four-Strand Bundled Conductor

The expressions for the geometric mean radius for the 2,3 , and 4 strands bundled conductors are presented in equations (8), (9), and (10).

$$
\begin{array}{lll}
D_{s(2)}^{b} & = & \sqrt{D_{s} \times d} \\
D_{s(3)}^{b} & = & \sqrt[3]{D_{s} \times d^{2}} \\
D_{s(4)}^{b} & = & 1.09 \sqrt[4]{D_{s} \times d^{3}}
\end{array}
$$

It is obvious that when equations (8), (9), and (10) are substituted for the space between the transmission lines conductors (d) in equation (4), the magnitude of the corona loss in equation (4) reduces with the increase in the space between the bundled conductors and the geometric mean radius of the bundled conductors $\left(\mathrm{D}^{\mathrm{b}}{ }_{\mathrm{s}}\right)$. This is demonstrated in the simulation results presented in Figures 4-8 respectively.

\section{IV.POWER LOSS MINIMIZATION WITH HESSIAN MATRIX TEST.}

Corona and Ohmic loss minimization is mathematically achieved in this work with an unconstrained optimization technique using the Hessian matrix test for positive definite solution. The objective function to be optimized is the total loss which include the Ohmic and the corona loss. The Hessian matrix is derived from the minimized expressions obtained from equations (11) to (23).

$$
\begin{aligned}
& \underset{(\mathrm{I}, \mathrm{V}, \mathrm{d})}{\operatorname{Minimize}} \mathrm{T}_{\mathrm{Loss}}=\mathrm{I}^{2} \frac{\rho \mathrm{L}}{\mathrm{A}} \\
& +\frac{242 \times(\mathrm{F}+25)}{\delta} \times \sqrt[4]{\left(\frac{\mathrm{A}}{\pi \mathrm{d}^{2}}\right)} \\
& \times\left(\mathrm{V}-\mathrm{V}_{0}\right)^{2} \\
& \times 10^{-5}(\mathrm{Kw} / \mathrm{Km} / \text { phase })
\end{aligned}
$$

The stationary points of equation (11) are determined by differentiating all the selected variables to form the Hessian matrix according to Rao [16].

$$
\begin{aligned}
\frac{\partial T_{\text {Loss }}}{\partial I}= & \frac{2 I \rho L}{A} \\
\frac{\partial T_{\text {Los }}}{\partial V}= & \frac{484 \times(\mathrm{F}+25)}{\delta} \times \sqrt[4]{\left(\frac{\mathrm{A}}{\pi \mathrm{d}^{2}}\right)} \times\left(\mathrm{V}-\mathrm{V}_{0}\right) \\
& \times 10^{-5} \\
\frac{\partial T_{\text {Loss }}}{\partial d}= & \frac{-121 \times(\mathrm{F}+25)}{\delta} \times \sqrt[4]{\left(\frac{\mathrm{A}}{\pi}\right)} \times\left(\mathrm{V}-\mathrm{V}_{0}\right)^{2} \times \mathrm{d}^{-\frac{3}{2}} \\
& \times 10^{-5}
\end{aligned}
$$

The Hessian matrix is obtained by taking the second derivatives of equations (12), (13), and (14).

$$
\frac{\partial^{2} T_{\text {Loss }}}{\partial I^{2}}=\frac{2 \rho L}{A}
$$




$$
\begin{aligned}
& \frac{\partial^{2} T_{\text {Loss }}}{\partial I \partial V}=0 \\
& \frac{\partial^{2} T_{\text {Loss }}}{\partial I \partial d}=0 \\
& \frac{\partial^{2} T_{\text {Loss }}}{\partial V \partial I}=0 \\
& \frac{\partial^{2} T_{\text {Loss }}}{\partial V^{2}}=\frac{484 \times(\mathrm{F}+25)}{\delta} \times \sqrt[4]{\left(\frac{\mathrm{A}}{\pi \mathrm{d}^{2}}\right)} \\
& \times 10^{-5}
\end{aligned}
$$

$\frac{\partial^{2} T_{\text {Loss }}}{\partial V \partial d}=\frac{-242 \times(\mathrm{F}+25)}{\delta} \times \sqrt[4]{\left(\frac{\mathrm{A}}{\pi}\right)} \times\left(\mathrm{V}-\mathrm{V}_{0}\right) \times \mathrm{d}^{-\frac{3}{2}}$

$$
\times 10^{-5}
$$

$$
\frac{\partial^{2} T_{L o s s}}{\partial d \partial \mathrm{I}}=0
$$

$$
\frac{\partial^{2} T_{\text {Loss }}}{\partial d \partial V}=\frac{-242 \times(\mathrm{F}+25)}{\delta} \times \sqrt[4]{\left(\frac{\mathrm{A}}{\pi}\right)} \times\left(\mathrm{V}-\mathrm{V}_{0}\right) \times \mathrm{d}^{-\frac{3}{2}}
$$

$$
\begin{aligned}
& \frac{\partial^{2} T_{\text {Loss }}}{\partial d^{2}}=\frac{363}{2 \delta} \frac{\mathrm{F}+25)}{2 \delta} \times \sqrt[4]{\left(\frac{\mathrm{A}}{\pi}\right)} \times\left(\mathrm{V}-\mathrm{V}_{0}\right)^{2} \times \mathrm{d}^{-\frac{5}{2}} \\
& \times 10^{-5}
\end{aligned}
$$

The Hessian matrix is represented in equation (24).

$\mathrm{H}$

$$
=\left(\begin{array}{lll}
\frac{\partial^{2} \mathrm{~T}_{\text {Loss }}}{\partial \mathrm{I}^{2}}=H_{11} & \frac{\partial^{2} \mathrm{~T}_{\text {Loss }}}{\partial \mathrm{I} \partial \mathrm{V}}=H_{12} & \frac{\partial^{2} \mathrm{~T}_{\text {Loss }}}{\partial \mathrm{I} \partial \mathrm{d}}=H_{13} \\
\frac{\partial^{2} \mathrm{~T}_{\text {Loss }}}{\partial \mathrm{V} \partial \mathrm{I}}=H_{21} & \frac{\partial^{2} \mathrm{~T}_{\text {Loss }}}{\partial \mathrm{V}^{2}}=H_{22} & \frac{\partial^{2} \mathrm{~T}_{\text {Loss }}}{\partial \mathrm{V} \partial \mathrm{d}}=H_{23} \\
\frac{\partial^{2} \mathrm{~T}_{\text {Loss }}}{\partial \mathrm{d} \partial \mathrm{I}}=H_{31} & \frac{\partial^{2} \mathrm{~T}_{\text {Loss }}}{\partial \mathrm{d} \partial \mathrm{V}}=H_{32} & \frac{\partial^{2} \mathrm{~T}_{\text {Loss }}}{\partial \mathrm{d}^{2}}=H_{33}
\end{array}\right)
$$

Substituting the equivalent expression of the second derivatives into the Hessian matrix results to equation (25).

$\mathrm{H}$

$$
=\left(\begin{array}{ccc}
\frac{2 I \rho L}{A} & 0 & 0 \\
0 & \frac{484 \times(\mathrm{F}+25)}{\delta} \times \sqrt[4]{\left(\frac{\mathrm{A}}{\pi \mathrm{d}^{2}}\right)} \times 10^{-5} & \frac{-242 \times(\mathrm{F}+25)}{\delta} \times \sqrt[4]{\left(\frac{\mathrm{A}}{\pi}\right)} \times\left(\mathrm{V}-\mathrm{V}_{0}\right) \times \mathrm{d}^{-\frac{3}{2}} \times 10^{-5} \\
0 & \frac{-242 \times(\mathrm{F}+25)}{\delta} \times \sqrt[4]{\left(\frac{\mathrm{A}}{\pi}\right)} \times\left(\mathrm{V}-\mathrm{V}_{0}\right) \times \mathrm{d}^{-\frac{3}{2}} \times 10^{-5} & \frac{363 \times(\mathrm{F}+25)}{2 \delta} \times \sqrt[4]{\left(\frac{\mathrm{A}}{\pi}\right)} \times\left(\mathrm{V}-\mathrm{V}_{0}\right)^{2} \times \mathrm{d}^{-\frac{5}{2}} \times 10^{-5}
\end{array}\right)
$$

The total power loss is minimized if the leading principal determinants for equation (25) are presented in equations determinants are positive and greater than zero for an (26), (27), and (28). optimized system. Therefore, the leading principal

$$
\begin{aligned}
& \left|H_{11}\right|=\left|\frac{2 I \rho L}{A}\right|>0 \\
& \left|\begin{array}{cc}
H_{11} & H_{12} \\
H_{21} & H_{22}
\end{array}\right|=\left|\begin{array}{cc}
\frac{2 I \rho L}{A} & 0 \\
0 & \frac{484 \times(\mathrm{F}+25)}{\delta} \times \sqrt[4]{\left(\frac{\mathrm{A}}{\pi \mathrm{d}^{2}}\right)} \times 10^{-5}
\end{array}\right|=\frac{968 \times(\mathrm{F}+25)}{A \times \delta} \times \sqrt[4]{\left(\frac{\mathrm{A}}{\pi \mathrm{d}^{2}}\right)} \times 10^{-5}>0 \\
& \left|\begin{array}{lll}
H_{11} & H_{12} & H_{13} \\
H_{21} & H_{22} & H_{23} \\
H_{31} & H_{32} & H_{33}
\end{array}\right|
\end{aligned}
$$

$$
=\left|\begin{array}{ccc}
\frac{2 I \rho L}{A} & 0 & 0 \\
0 & \frac{484 \times(\mathrm{F}+25)}{\delta} \times \sqrt[4]{\left(\frac{\mathrm{A}}{\pi \mathrm{d}^{2}}\right)} \times 10^{-5} & \frac{-242 \times(\mathrm{F}+25)}{\delta} \times \sqrt[4]{\left(\frac{\mathrm{A}}{\pi}\right)} \times\left(\mathrm{V}-\mathrm{V}_{0}\right) \times \mathrm{d}^{-\frac{3}{2}} \times 10^{-5} \\
0 & \frac{-242 \times(\mathrm{F}+25)}{\delta} \times \sqrt[4]{\left(\frac{\mathrm{A}}{\pi}\right)} \times\left(\mathrm{V}-\mathrm{V}_{0}\right) \times \mathrm{d}^{-\frac{3}{2}} \times 10^{-5} & \frac{363 \times(\mathrm{F}+25)}{2 \delta} \times \sqrt[4]{\left(\frac{\mathrm{A}}{\pi}\right)} \times\left(\mathrm{V}-\mathrm{V}_{0}\right)^{2} \times \mathrm{d}^{-\frac{5}{2}} \times 10^{-5}
\end{array}\right|
$$


Corona Loss Minimization on High Voltage Transmission Line Network using Bundled Conductors.

$$
\begin{aligned}
&=\frac{2 I \rho L}{A}\left[\left(\frac{484 \times(\mathrm{F}+25)}{\delta} \times \sqrt[4]{\left(\frac{\mathrm{A}}{\pi \mathrm{d}^{2}}\right)} \times 10^{-5}\right)\right. \\
& \times\left(\frac{363 \times(\mathrm{F}+25)}{2 \delta} \times \sqrt[4]{\left(\frac{\mathrm{A}}{\pi}\right)} \times\left(\mathrm{V}-\mathrm{V}_{0}\right)^{2}\right. \\
&\left.\times \mathrm{d}^{-\frac{5}{2}} \times 10^{-5}\right)
\end{aligned}
$$$$
\begin{aligned}
& -\left(\frac{242 \times(\mathrm{F}+25)}{\delta} \times \sqrt[4]{\left(\frac{\mathrm{A}}{\pi}\right)} \times\left(\mathrm{V}-\mathrm{V}_{0}\right)\right. \\
& \left.\left.\times \mathrm{d}^{-\frac{3}{2}} \times 10^{-5}\right)\right] \\
& >0
\end{aligned}
$$

Since all the leading principal determinants are greater than zero, it is evident that the Hessian matrix for the total power loss on the transmission line is positive definite. This implies that the power loss on the transmission line can only be minimized if the flowing current gets to zero and when the operating voltage $(\mathrm{V})$ assumes a value close to the critical disruptive voltage $\left(\mathrm{V}_{0}\right)$ with an infinite distance of conductor spacing (d).

\section{SIMULATION RESULTS AND DISCUSSION.}

Simulation was carried out with the aid of the corona loss equation presented in (4). The simulation parameters are shown in Table 1. A plot of corona loss against an unbundled conductor spacing is presented in Figure 4. It is observed that an exponential decrease in the magnitude of corona loss is obtained with an increase in the conductor spacing as shown in Figure 4. When 2, 3, and 4 strands of bundled conductor are incorporated, it is also observed that the rate of corona loss is decreased with an increased number of bundled conductors as shown in Figures 5, 6, and 7. This is evident in Figure 7 which has a much reduced value of corona loss for a four bundled conductor with more spacing distance. The plot of voltage gradient presented in Figure 8 showed that the voltage gradient attained a minimum value when the sub-conductor spacing is increased which conformed to the principle earlier presented.

Table 1. Simulation Parameters [10].

\begin{tabular}{|l|l|}
\hline Estimated Corona Parameters & Values \\
\hline Barometric Pressure P (cmHg) & 72.2 \\
\hline Ambient Temperature t $\left.{ }^{\circ} \mathrm{C}\right)$ & 25 \\
\hline Air Density Factor $\delta$ & 0.95 \\
\hline $\begin{array}{l}\text { Frequency of Transmission } \\
\text { Voltage F (Hz) }\end{array}$ & 50 \\
\hline Radius of The Conductor R (cm) & 1.2 \\
\hline $\begin{array}{l}\text { Spacing Between The } \\
\text { Transmission Lines Conductors D } \\
(\mathrm{cm})\end{array}$ & $200,400,600$, \\
\hline $\begin{array}{l}\text { Separation between Sub- } \\
\text { Conductors S (cm) }\end{array}$ & 14.64 \\
\hline $\begin{array}{l}\text { Transmission Line Voltage V } \\
(\mathrm{kV})\end{array}$ & $330 \mathrm{kV}$ \\
\hline $\begin{array}{l}\text { Estimated Critical Disruptive } \\
\text { Voltage } \mathrm{V}_{0}(\mathrm{kV})\end{array}$ & 21.1 \\
\hline $\begin{array}{l}\text { Cross Sectional Area of the } \\
\left.\text { conductor A (cm }{ }^{2}\right)\end{array}$ & 4.524 \\
\hline Conductors Length L (m) & $250-300$ \\
\hline
\end{tabular}




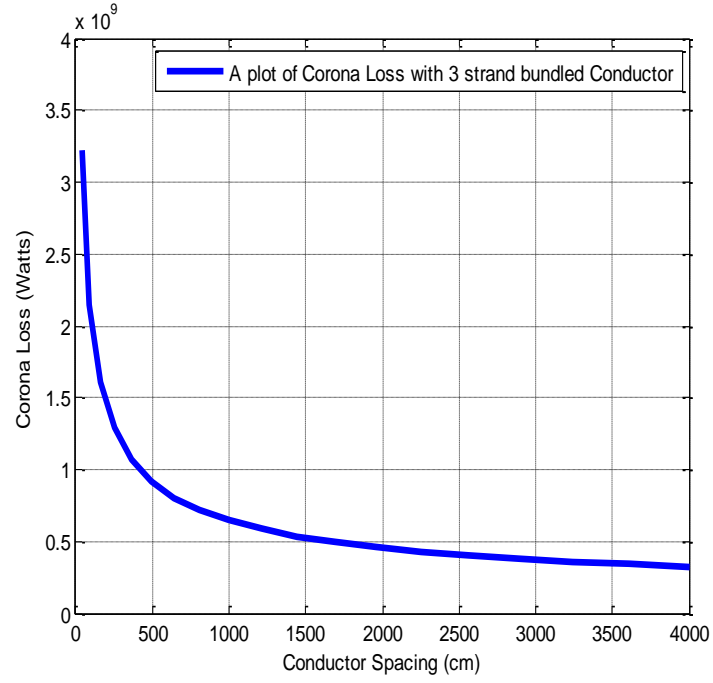

Figure 6. A plot of Corona Loss against 3-strands bundled Conductor Spacing (d).

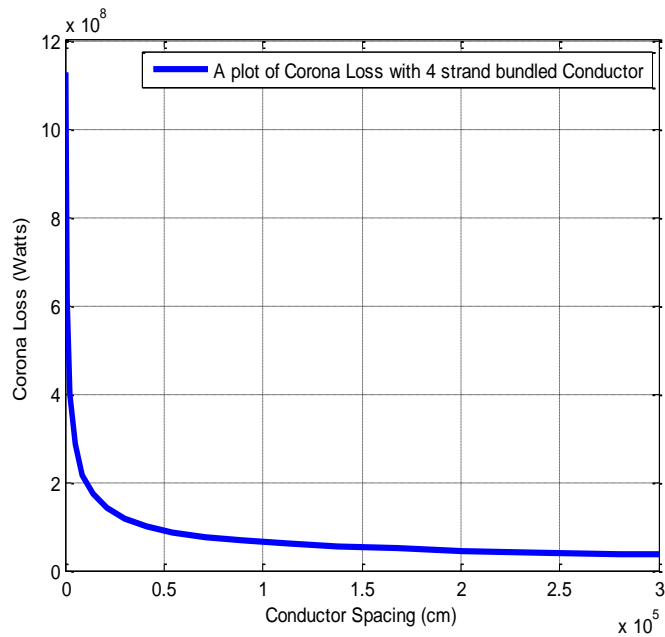

Figure 7. A plot of Corona Loss against 4-strands

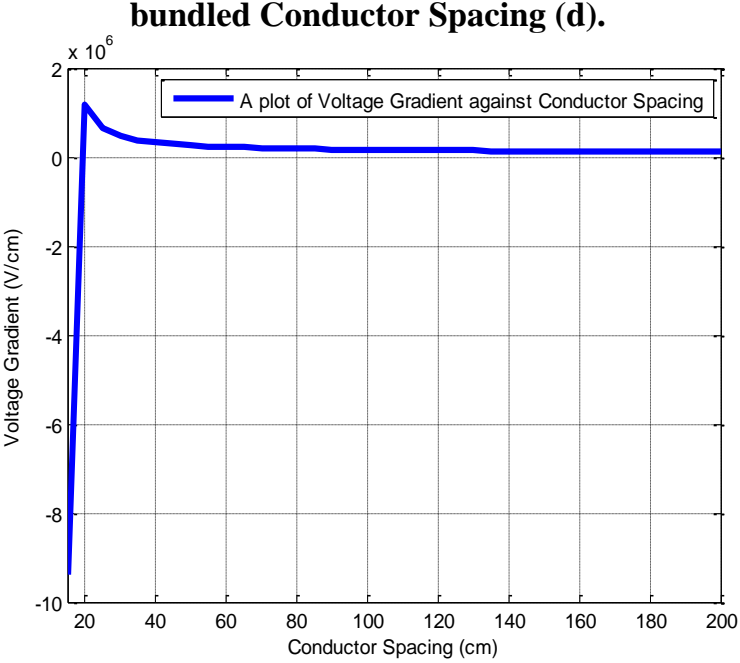

Figure 8. A plot of Voltage Gradient against Conductor Spacing (d).

\section{VI.CONCLUSION}

Analysis of transmission line power loss minimization has been presented. The Hessian matrix stability test was carried out on the optimized power loss equation. The leading principal determinants of the unconstrained optimized equations gave a value above zero which satisfied a positive definite condition. Simulation results obtained for the corona loss with an increased conductor spacing for a 2, 3, and 4 bundled conductors showed a sharp exponential decrease as the conductor bundling is increased beyond two. The voltage gradient also decreased with an increased conductor spacing as presented in the simulation result which conformed to the existing reported literature. This obvious decrease in corona loss and voltage gradient on the transmission lines with a resultant increase in the space between conductors validates this research.

\section{REFERENCES}

1. V.K. Mehta, and R. Mehta, Principles of Power Systems. S. Chand Company Ltd, India 2008.

2. B.O. Anyaka, and O.I. Olawoore, "Minimization of Losses on Transmission Lines," Journal of Electrical and Electronics Engineering (IOSR-JEE), Vol.9, Issue 3, pp. 23-26, 2014.

3. M.A. Zakariya, "Corona Power Loss versus Ohmic Power Loss in HV Transmission Lines," Proceedings of the Dhahran Power Conference, August, 2010.

4. S. Numphetch, L. Uthen, K. Umapron, U. Dusit, and K. Thamatchai, "Loss Minimization using Optimal Power Flow based on Swarm Intelligence," ECTI Transaction on Electrical, Electronic and Communication Engineering, Vol. 9, No.1, pp. 212-222, 2011.

5. T. Thabendra, N. Yaw, K.S. Sanjeev, R. Bhuvana, and A.C. David, "Multi-Objective Optimization Methods for Power Loss Minimization and Voltage Stability," Journal of Advanced Power Systems, Vol. 9, No.2, pp. 1-10, 2009

6. N.R.H. Abdullah, M. Ismail, and M.O. Mohammed, “Transmission Loss Minimization and Power Installation Cost Using Evolutionary Computation for Improvement of Voltage Stability," Proceedings of the $14^{\text {th }}$ International Middle East Power Systems Conference, 2010.

7. F.G. Bagriyanik, Z.E. Aygen, "Power Loss Minimization Using Fuzzy Multi-Objective Formulation and Genetic Algorithm," Proceedings of the Bologna IEEE Power Tech. Conference, 2003.

8. M.F. Moghadam and H.A. Berghmandpour, "A New Method for Calculating Transmission Power Losses Based on Exact Modelling of Ohmic Loss," Proceedings of the $25^{\text {th }}$ International Power Conference, 2010

9. C.I. Wadhwa, Electrical Power Systems, New Age International Publishers Ltd, India. 2009.

10. A.K. Theraja and B.L. Theraja, Electrical Engineering Technology, S. Chand Company Ltd New Delhi, India. 2004.

11. A.M. James, Electric Power System Applications and Optimization. McGraw-Hill Company Ltd, 2005.

12. A.O. Ibe, Power System Analysis. Odus Press Printer and Publishers Uwani Enugu, Nigeria. 2002.

13. Hadi, Saadat. Power System Analysis. McGraw-Hill Companies Inc. USA, 1999.

14. B.M. Weedy, Electric Power Systems. Third Edition, John Wiley and Sons, Inc. New York, 1979.

15. W.D. Stevenson, and J.J. Grainger, Power System Analysis, McGrawHill Book Company, New York, 1994.

16. S.S. Rao, Optimization Theory and Application, John Wiley Eastern Limited New York, 1998.

\section{AUTHORS PROFILE}

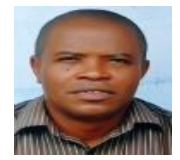

Crescent Onyebuchi Omeje received his Bachelor's degree in Electrical Engineering, in 2004 from University of Nigeria, Nsukka. He also obtained his Masters of Engineering (M.Eng) and Doctor of Philosophy (Ph.D) with distinction in 2011 and 2019 respectively in Electrical Engineering, from the same University. He is a Member of Nigeria Society of Engineers (MNSE), a registered member Council of the regulation of Engineering in Nigeria (COREN), a member of the Institute of Electrical/Electronic Engineering (IEEE) and a full-time lecturer in the Department of Electrical/Electronic Engineering, University of Port Harcourt, Rivers State, Nigeria. His research interests are on power electronics, new energy conversion systems, multilevel inverter applications, smart grid intelligent systems, and Electric motor drives. email:crescent.omeje@uniport.edu.

ng

Published By: 